\title{
Aplikasi Perhitungan Angka Kredit Point Pengajuan Kenaikan Pangkat Guru pada Dinas Pendidikan dan Kebudayaan Kota Bengkulu
}

\author{
Sapri $^{1}$ \\ ${ }^{1}$ Dosen Tetap Program Studi Teknik Informatika Fakultas Ilmu Komputer Universitas Dehasen Bengkulu \\ Jl. Meranti Raya No. 32 Kota Bengkulu 38228 Telp. (0736) 22027, 26957 Fax. (0736) 341139; e-mail: sapri@unived.ac.id)
}

\begin{abstract}
This study is to create an application for calculating credit points for submission of teacher ranks at the Bengkulu City Education and Culture Office using Visual Basic 6 Programming Languages. System design uses structured data modeling, namely Entity Relationship Diagram (ERD) to describe data models and Data Flow Diagrams (DFD ) to describe the functional model. This application can do Calculation of Credit Point Points for Submitting Teacher Ranks to the Bengkulu City Education and Culture Office.
\end{abstract}

Keyword: Application of Calculation of Credit Point Points, Submission of Rank

Intisari- Penelitian ini untuk membuat Aplikasi Perhitungan Angka Kredit Point Pengajuan Kenaikan Pangkat Guru Pada Dinas Pendidikan dan Kebudayaan Kota Bengkulu menggunakan Bahasa Pemrograman Visual Basic 6. Perancangan sistem menggunakan pemodelan datanya terstruktur yaitu Entity Relationship Diagram (ERD) untuk menggambarkan model data dan Data Flow Diagram (DFD) untuk menggambarkan model fungsional. Aplikasi ini dapat melakukan Perhitungan Angka Kredit Point Pengajuan Kenaikan Pangkat Guru Pada Dinas Pendidikan dan Kebudayaan Kota Bengkulu.

Kata Kunci: Aplikasi Perhitungan Angka Kredit Point, Pengajuan Pangkat

\section{PENDAHULUAN}

Perkembangan teknologi informasi dewasa ini sangat pesat dan hampir menyentuh seluruh aktivitas yang dilakukan oleh manusia. Salah satu kemajuan teknologi tersebut adalah makin berkembangnya mesin-mesin kantor antara lain penggunaan komputer dalam mendukung pekerjaan kantor dan yang memberikan bantuan besar untuk menunjang efektifitas kinerja kantor tersebut. Pemanfaatan teknologi seperti penggunaan bermacam-macam aplikasi. Aplikasi merupakan suatu perangkat lunak (software) yang sudah banyak digunakan berbagai instansi maupun perusahaan swasta. Komputer yang ada saat ini telah membantu karyawan dalam meyelesaikan pekerjaan dengan cepat sehingga memberikan pelayanan yang lebih optimal kepada masyarakat yang membutuhkan.
Pendidikan merupakan salah satu aspek terpenting dalam meningkatkan kualitas manusia. Oleh karena itu perkembangan pendidikan harus mampu menjamin pemerataan kesempatan memperoleh layanan pendidikan, peningkatan mutu dan efisiensi manajemen pendidikan untuk menghadapi tantangan sesuai dengan tuntunan perubahan kehidupan lokal, nasional, dan globalisasi.

Kantor Dinas Pendidikan dan Kebudayaan Kota Bengkulu merupakan salah satu instansi pemerintah yang kegiatannya berhubungan dengan peningkatan mutu dan kualitas pendidikan tersebut di wujudkan pada peran pemerintahan dalam peningkatan pendidikan, yang telah di atur dalam UUD Negara Republik Indonesia 1945 (Amandemen IV) yang menyatakan bahwa setiap warga Negara wajib mengikuti pendidikan dasar dan pemerintah wajib meningkatkannya.

Dengan kebijakan inilah diharapkan kualitas layanan pendidikan dilembaga pendidikan dalam menentukan kualitas lulusan sebagai output utama dari system pendidikan dapat ditingkatkan, namun upaya perbaikan layanan pada lembaga pendidikan tidak sederhana yang dipikirkan karena masalah layanan yang tampak belum tentu merupakan permasalahan yang sebenarnya, dengan demikian peneliti membuat dan mengembangkan suatu aplikasi pada Dinas Pendidikan dan Kebudayaan Kota Bengkulu dengan judul: “Aplikasi Perhitungan Angka Kredit Point Pengajuan Kenaikan Pangkat Guru Pada Dinas Pendidikan dan Kebudayaan Kota Bengkulu”.

Tujuan dari penelitian ini adalah untuk membuat Aplikasi Perhitungan Angka Kredit Point Pengajuan Kenaikan Pangkat Guru Pada Dinas Pendidikan dan Kebudayaan Kota Bengkulu menggunakan Pemrograman PHP yang nantinya diharapkan dapat membantu dan 
bermanfaat bagi Dinas Pendidikan dan Kebudayaan Kota Bengkulu dalam menghitung angka kredit point pegawai.

\section{Tinjauan Pustaka}

\section{A. Pengertian Aplikasi}

Aplikasi merupakan Program siap pakai yang dapat digunakan untuk menjalankan printah-printah dari pengguna aplikasi tersebut dengan tujuan mendapatkan hasil yang lebih akurat sesuai dengan tujuan pembuatan aplikasi tersebut, aplikasi mempunyai arti yaitu pemecahan masalah yang menggunakan salah satu tehnik pemrosesan data aplikasi yang biasanya berpacu pada sebuah komputansi yang diinginkan atau diharapkan maupun pemrosesan data yang diharapkan

Beberapa aplikasi yang digabung bersama menjadi suatu paket kadang disebut sebagai suatu paket atau suite aplikasi (application suite). Contohnya adalah Microsoft Office dan OpenOffice.org, Bahasa Pemrograman yang menggabungkan suatu aplikasi pengolah kata, lembar kerja, serta beberapa aplikasi lainnya. Aplikasi-aplikasi dalam suatu paket biasanya memiliki antarmuka pengguna yang memiliki kesamaan sehingga memudahkan pengguna untuk mempelajari dan menggunakan tiap aplikasi. Penggolongan Aplikasi

1. Perangkat lunak perusahaan (enterprise)

2. Perangkat lunak infrastruktur perusahaan

3. Perangkat lunak informasi kerja

4. Perangkat lunak media dan hiburan

5. Perangkat lunak pendidikan

6. Perangkat lunak pengembangan media

7. Perangkat lunak rekayasa produk

Selain itu aplikasi juga mempunyai fungsi sebagai pelayan kebutuhan beberapa aktivitas yang dilakukan oleh manusia seperti sistem untuk software jual beli, permainan atau game online.

\section{B. Angka Kredit Point Kenaikan Pangkat Guru}

Menurut Peraturan Menteri Negara

Pendayagunaan Aparatur negara dan Reformasi Birokrasi Nomor 16 Tahun 2009 Tentang Jabatan Fungsional Guru dan Angka Kreditnya. Bab I Ketentuan Umum Pasal 1, angka kredit adalah satuan nilai dari tiap butir kegiatan dan/atau akumulasi nilai butir-butir kegiatan yang harus dicapai oleh seorang Guru dalam rangka pembinaan karier kepangkatan dan jabatannya.

Jabatan fungsional guru merupakaqn jabatan fungsional yang mempunyai ruang lingkup, tugas, tanggung jawab, dan wewenang untuk melakukan kegiatan mendidik, mengajar, membimbing, mengarahkan, melatih, menilai, dan mengevaluasi peserta didik pada pendidikan anak usia dini jalur pendidikan formal, pendidikan dasar, dan pendidikan menengah sesuai dengan peraturan perundang-undangan yang diduduki oleh Pegawai Negeri Sipil

Berdasarkan Peraturan Menteri Pendayagunaan Aparatur Negara dan Reformasi Birokrasi (Permen PAN RB) No 16 Tahun 2009 Tanggal 10 November 2009, maka mulai tahun 2013 bagi Guru PNS yang akan mengusulkan kenaikan pangkatnya harus memenuhi beberapa kriteria antara lain adalah kredit point yang harus didapat dalam pengembangan diri dan karya tulis. Lebih jelasnya lihatpenjelasan berikut ini :

1. Kenaikan pangkat dari IIIA ke IIIB guru wajib melaksanakan kegiatan pengembangan diri (Pelatihan dan Kegiatan Kolektif Guru) yang besarnya 3 angka kredit

2. Kenaikan pangkat IIIB ke IIIC guru wajib melaksanakan kegiatan pengembangan diri yang besar angka kreditnya 3 dan publikasi Karya Ilmiah atau Karya Inovatif (KTI, Membuat Alat Peraga, Alat Pembelajaran, Karya Teknologi/Seni) dengan 4 angka Kredit

3. Kenaikan Pangkat IIIC ke IIID guru wajib melaksanakan kegiatan pengembangan diri yang besar kredit 3 dan publikasi Karya Ilmiah atau karya inovatif dengan 6 angka kredit

4. Kenaikan Pangkat IIID ke IVA guru wajib melaksanakan kegiatan pengembangan diri dengan 4 angka kredit dan Publikasi Karya Ilmiah atau Karya Inovatif dengan 8 angka kredit

5. Kenaikan Pangkat IVA ke IVB guru wajib melaksanakan kegiatan pengembangan diri dengan 4 
angka kredit serta Publikasi Karya Ilmiah atau Karya Inovatif dengan 12 angka kredit

6. Kenaikan pangkat IVBke IVC guru wajib melaksanakan kegiatan pengembangan diri dengan 4 angka kredit serta publikasi karya Ilmiah dengan 12 angka kredit

7. Kenaikan pangkat IVC ke IVD guru wajib melaksanakan kegiatan pengembangan diri dengan 5 angka kredit serta Publikasi karya ilmiah/Inovatif dengan 14 angka kredit

8. Kenaikan Pangkat IVD ke IVE guru wajib melaksanakan kegiatan pengembangan diri dengan 5 angka kredit serta publikasi karya ilmiah/inovatif dengan 20 angka kredit

Tabel 1. Angka Kredit Untuk Kenaikan Pangkat Guru

\begin{tabular}{|c|c|c|c|c|}
\hline $\begin{array}{l}\text { Tingkat } \\
\text { Jabatan }\end{array}$ & Gol & Angka Kredit & Karir & $\begin{array}{c}\text { Lama } \\
\text { dalam gol }\end{array}$ \\
\hline \multirow{2}{*}{$\begin{array}{l}\text { GURU } \\
\text { UTAMA }\end{array}$} & $\mathrm{IV} / \mathrm{e}$ & Akhir jabatan & $\begin{array}{l}\text { Guru dan } \\
\text { semua } \\
\text { jabatan } \\
\text { pengelola } \\
\text { an; } \\
4 \text { tahun }\end{array}$ & $\begin{array}{l}\text { Akhir } \\
\text { jabatan; } \\
\text { Tidak ada } \\
\text { batas }\end{array}$ \\
\hline & $\mathrm{IV} / \mathrm{d}$ & $\begin{array}{l}200 ; \quad 5 \text { dari } \\
\text { pengembangan } \\
\text { diri; 20 dari } \\
\text { publikasi ilmiah } \\
\text { dan/atau karya } \\
\text { inovatif; }\end{array}$ & $\begin{array}{l}\text { Guru dan } \\
\text { semua } \\
\text { jabatan } \\
\text { pengelola } \\
\text { an; } \\
4 \text { tahun }\end{array}$ & $\begin{array}{l}\text { Min. } \\
\text { tahun; } \\
\text { Total } \\
\text { kumulatif } \\
32 \text { tahun }\end{array}$ \\
\hline \multirow{3}{*}{$\begin{array}{l}\text { GURU } \\
\text { MADYA }\end{array}$} & $\mathrm{IV} / \mathrm{c}$ & $\begin{array}{l}150 ; \quad 5 \quad \text { dari } \\
\text { pengembangan } \\
\text { diri; } 14 \quad \text { dari } \\
\text { publikasi ilmiah } \\
\text { dan/atau karya } \\
\text { inovatif; } \\
\text { presentasi ilmiah }\end{array}$ & $\begin{array}{l}\text { Guru dan } \\
\text { semua } \\
\text { jabatan } \\
\text { pengelola } \\
\text { an; } \\
4 \text { tahun }\end{array}$ & $\begin{array}{l}\text { Min. } 4 \\
\text { tahun total } \\
12 \text { tahun; } \\
\text { Total } \\
\text { kumulatif } \\
28 \text { tahun }\end{array}$ \\
\hline & $\mathrm{IV} / \mathrm{b}$ & $\begin{array}{lr}150 ; \quad 4 & \text { dari } \\
\text { pengembangan } \\
\text { diri; 12 } \\
\text { publikasi } & \text { ilmiah } \\
\text { dan/atau } & \text { karya } \\
\text { inovatif; } & \end{array}$ & $\begin{array}{l}\text { Guru dan } \\
\text { semua } \\
\text { jabatan } \\
\text { pengelola } \\
\text { an; } \\
4 \text { tahun }\end{array}$ & $\begin{array}{l}\text { Min. } \\
\text { tahun }\end{array}$ \\
\hline & IV/a & $\begin{array}{lr}150 ; \quad 4 & \text { dari } \\
\text { pengembangan } \\
\text { diri; } 12 & \text { dari } \\
\text { publikasi } & \text { ilmiah } \\
\text { dan/atau } & \text { karya } \\
\text { inovatif; } & \\
\end{array}$ & $\begin{array}{l}\text { Guru dan } \\
\text { semua } \\
\text { jabatan } \\
\text { pengelola } \\
\text { an; } \\
4 \text { tahun } \\
\end{array}$ & $\begin{array}{l}\text { Min. } \\
\text { tahun }\end{array}$ \\
\hline \multirow{2}{*}{$\begin{array}{l}\text { GURU } \\
\text { MUDA }\end{array}$} & $\mathrm{III} / \mathrm{d}$ & 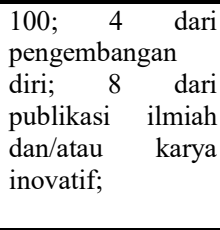 & $\begin{array}{l}\text { Guru dan } \\
\text { semua } \\
\text { jabatan } \\
\text { pengelola } \\
\text { an; } \\
4 \text { tahun }\end{array}$ & $\begin{array}{ll}\text { Min. } & 4 \\
\text { tahun } & \\
\text { Total } & 8 \\
\text { tahun } & \\
\text { Total } & \\
\text { kumulatif } & \\
16 \text { tahun }\end{array}$ \\
\hline & $\mathrm{III} / \mathrm{c}$ & 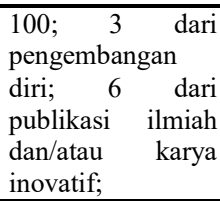 & $\begin{array}{l}\text { Guru dan } \\
\text { semua } \\
\text { jabatan } \\
\text { pengelola } \\
\text { an; } \\
4 \text { tahun }\end{array}$ & $\begin{array}{l}\text { Min. } \\
\text { tahun }\end{array}$ \\
\hline GURU & $\mathrm{III} / \mathrm{b}$ & $50 ; \quad 3$ & Guru; 4 & Min. \\
\hline
\end{tabular}

\begin{tabular}{|c|c|c|c|c|}
\hline $\begin{array}{l}\text { Tingkat } \\
\text { Jabatan }\end{array}$ & Gol & Angka Kredit & Karir & $\begin{array}{c}\text { Lama } \\
\text { dalam gol }\end{array}$ \\
\hline \multirow[t]{2}{*}{$\begin{array}{l}\text { PERTA } \\
\text { MA }\end{array}$} & & \begin{tabular}{lr}
\multicolumn{3}{l}{ pengembangan } \\
diri; 4 & dari \\
publikasi & ilmiah \\
dan/atau & karya \\
inovatif; & \\
\end{tabular} & tahun & $\begin{array}{l}\text { tahun } \\
\text { Total } \quad 8 \\
\text { tahun }\end{array}$ \\
\hline & $\mathrm{III} / \mathrm{a}$ & $\begin{array}{l}50 ; \quad 3 \quad \text { dari } \\
\text { pengembangan } \\
\text { diri; }\end{array}$ & $\begin{array}{ll}\text { Guru; } & 4 \\
\text { tahun } & \end{array}$ & $\begin{array}{l}\text { Min. } \\
\text { tahun }\end{array}$ \\
\hline
\end{tabular}

Adapun Tahap penghitungan angka kredit untuk kenaikan pangkat guru adalah sebagai berikut :

1) Rekap Hasil Penilaian Kinerja Guru Kelas/Mata Pelajaran, hasil penilaian kinerja guru Kelas/Mata Pelajaran/Bimbingan dan Konseling/Konselor sesuai dengan masing-masing kompetensinya. Selanjutnya hasil penilaian dari setiap kompetensi dijumlahkan sebagai skor penilaian kinerja guru yang belum dikonversikan kepada ketentuan Permenegpan dan RB Nomor 16 Tahun 2009.

2) Skala Konversi hasil PK Guru berdasarkan Permenegpan dan RB Nomor 16 Tahun 2009. Selanjutnya hasil di atas dilakukan konversi berdasarkan Permenegpan dan RB Nomor 16 Tahun 2009 dengan menggunakan rumus Skala Konversi pada tabel berikut:

Tabel 2. Skala Nilai PK

\begin{tabular}{|c|c|c|}
\hline $\begin{array}{c}\text { Permenneg PAN dan } \\
\text { RB No.16 tahun 2009 } \\
\text { (Skala 0- 100) }\end{array}$ & Sebutan & $\begin{array}{c}\text { Persentase } \\
\text { Angka kredit } \\
\text { yang diperoleh }\end{array}$ \\
\hline $91-100$ & Amat baik & $125 \%$ \\
\hline $76-90$ & Baik & $100 \%$ \\
\hline $61-75$ & Cukup & $75 \%$ \\
\hline $51-60$ & Sedang & $50 \%$ \\
\hline$\leq 50$ & Kurang & $25 \%$ \\
\hline
\end{tabular}

3) Rumus yang digunakan menghitung angka kredit, sebagai berikut.

1. Perolehan angka kredit untuk pembelajaran atau pembimbingan setiap tahun bagi guru diperhitungkan dengan rumus sebagai berikut :

Angka Kredit Pertahun $=\frac{(\text { AKK }- \text { AKPKB }- \text { AKP }) \times \text { JM/JWM } \times \text { NPK }}{4}$

2. Untuk menghitung angka kredit unsur tugas tambahan yang relevan dengan fungsi sekolah digunakan rumus berikut ini.

Angka Kredit Pertahun $=\frac{(\mathrm{AKK}-\mathrm{AKPKB}-\mathrm{AKP}) \times \mathrm{NPK}}{4}$ 
Adapun persyaratan Kenaikan Pangkat Pada Dinas Pendidikan dan Kebudayaan Kota Bengkulu adalah sebagai berikut :

\section{Syarat Naik Pangkat (dari III/b s.d IV/c)}

1. Dupak

2. Nip Baru

3. Karpeg

4. Sk Terakhir

5. Pak Lama

6. Pak Inpassing

7. Sk Mutasi Dari Gubernur dan Walikota (Jika Pindahan dari Luar Kota)

8. SK Mutasi Dari Walikota (Jika Pindahan Dalam Kota)

9. SK Capeg

10. SK PNS

11. Ijazah Terakhir (Legalisir Perguruan Tinggi yang Mengeluarkan)

12. DP 3 (2 TahunTerakhir)

13. NUPTK

\section{Tinjauan Umum Bahasa Pemrograman}

Menurut Adi Kurniadi (2000 : 349) Microsoft Visual Basic (VB) salah satu bahasa pemograman yang lengkap namun mudah untuk dipelajari. Bahasa pemrograman adalah perintah-perintah yang dimengerti oleh komputer untuk melakukan tugas-tugas tertentu. Bahasa pemrograman Visual Basic yang dikembangkan oleh Microsoft sejak tahun 1991, merupakan pengembangan dari pendahulunya yaitu bahasa pemrograman BASIC (Beginner's All-purpose Symbolic Instruction Code) yang dikembangkan pada era 1950-an. Visual Basic merupakan Development Tool yaitu alat bantu untuk membuat berbagai macam program komputer, khususnya yang menggunakan sistem operasi Windows. Visual Basic merupakan bahasa pemrograman komputer yang mendukung object OOP (Object Oriented Programming).

\section{Konsep Perancangan Database}

Menurut Yakub (2012:51), Basis data (database) merupakan kumpulan data yang saling berhubungan (punya relasi). Relasi biasanya ditunjukkan dengan kunci (key) dari tiap file yang ada. Dalam satu file terdapat record-record yang sejenis, sama besar, sama bentuk, yang merupakan satu kumpulan entitas yang seragam. Satu record terdiri dari field-field yang saling berhubungan dan menunjukkan dalam satu pengertian yang lengkap dalam satu record.

Menurut Fahlevi (2013:1) Basis data adalah sekumpulan data yang saling berhubungan secara logis dan terorganisir dengan baik. Kumpulan data tersebut yang saling berhubungan yang disimpan secara bersama sedemikian rupa dan tanpa pengulangan (redudansi) yang tidak perlu, untuk memenuhi berbagai kebutuhan. Kumpulan file atau arsip yang saling berhubungan yang disimpan dalam media penyimpanan elektronis. Dan menurut Supriyanto (2008:71) basis data adalah kumpulan dari berbagai file yang saling berhubungan membentuk jaringan informasi. Sedangkan menurut Bahri (2008:264) database adalah informasi yang diorganisasikan dan disimpan dengan cara tertentu, seperti DBMS (Database Management System).

Menurut Yakub (2012:55), Data Flow Diagram (DFD) merupakan alat untuk membuat diagram yang serbaguna. DFD / DAD terdiri dari 2 bagian yaitu :
a. DFD Context
b. DFD Level

Ada empat elemen yang menyusun suatu DFD, yaitu:

1) Proses

2) Data flow

3) Data Store

4) External entity

Masing-masing elemen akan diberi akan diberi lambang tertentu ERD (Entity Relation Diagram)

Menurut Yakub (2012:60), Entity Relation Diagram (ERD) merupakan suatu model jaringan yang menggunakan susunan data yang disimpan pada sistem secara abstrak. Entity Relation Diagram (ERD) juga menggambarkan hubungan antara satu entitas yang memiliki sejumlah atribut dengan entitas yang lain dalam suatu sistem yang terintegrasi. Berikut simbol-simbol ysng digunakan dalam ERD.

Kardinalitas Relasi (derajat relasi) menunjukkan jumlah maksimum entitas yang dapat berelasi dengan entitas pada himpunan entitas yang lain. Kardinalitas di 
antara dua himpunan entitas (misal A dan B) dapat berupa:

1) Satu ke satu (one to one / 1:1)

2) Satu ke Banyak (one to many / $1: M$ )

3) Banyak ke Satu (many to one / $M: 1$ )

4) Banyak ke Banyak (many to many / $M: N$ )

\section{Metodologi Penelitian}

\section{A. Metode Penelitian}

Metode penelitian yang digunakan pada penelitian ini adalah metode pengembangan sistem. Metode ini adalah sebuah cara yang tersistem atau teratur yang bertujuan untuk melakukan analisa pengembangan suatu sistem agar sistem tersebut dapat memenuhi kebutuhan pemakai.

\section{1) Perangkat Lunak (Software)}

Software yang digunakan dalam penelitian ini :

1. Sistem Operasi Windows 8.1 Pro

2. Macromedia Dreamweaver 8.0

3. $X A M P P$

4. Mozila Firefox

2) Perangkat Keras (Hardware)

Hardware yang digunakan yaitu :

1. Laptop Intel Core $i 3$

2. RAM $2 \mathrm{~GB}$

3. Harddisk $500 \mathrm{~GB}$

4. Printer Canon Pixma MP 287

5. Modem GSM 3G

\section{B. Metode Pengumpulan data}

Dalam penyusunan skripsi ini untuk mendapatkan hasil yang lebih baik maka penulis menggunakan metode pengumpulan data yaitu:

\section{1) Observasi}

Yaitu suatu teknik pengumpulan data yang penulis lakukan dengan pengamat secara langsung pada Dinas Pendidikan dan Kebudayaan Kota Bengkulu, serta hal-hal yang berhubungan penulis skripsi ini, guna mendapatkan data-data yang akurat.

\section{2) Wawancara}

Yaitu metode pengumpulan data yang dilakukan dengan cara melakukan wawancara dengan ketua atau yang mewakilinya sebagai pelengkap penyusunan penelitian pada Dinas Pendidikan dan Kebudayaan Kota Bengkulu yaitu Ibu Rosna Dewi, S.Pg.

\section{3) Studi Pustaka}

Yaitu metode pengumpulan data yang dilakukan oleh penulis dengan cara mempelajari buku-buku yang ada hubunganya dengan judul yang penulis angkat.

\section{Metode Perancangan Sistem}

1) Analisa Sistem Aktual

Berdasarkan hasil observasi saat prapenelitian di Dinas Pendidikan dan Kebudayaan Kota Bengkulu, proses perhitungan kredit point untuk pengajuan naik pangkat guru masih manual atau menggunakan Microsoft Excel. Untuk itu, di perlukan sistem baru yang dapat membantu dalam proses perhitungan kredit point untuk pengajuan naik pangkat guru agar hal yang didapatkan lebih akuran dan cepat.

\section{2) Analisa Sistem Baru}

Dalam perancangan sistem ini nantinya akan dibuat aplikasi perhitungan kredit point untuk pengajuan naik pangkat guru dengan menggunakan Bahasa Pemrograman VB 6.0. Tahapan yang dilakukan yaitu dengan merancang Basis Data (Database). Sebelum melakukan perancangan sistem akan dibahas pencariaan angka kredit point secara manual sebagai berikut:

$$
\begin{aligned}
\text { Angka Kredit per tahun } & =\frac{(A K K-A K P K B-A K P) x(J M / J W M) x N P K}{4} \\
& =\frac{\{(50-3-5) \times 24 / 24 \times 75 \%\}}{4}=7,88
\end{aligned}
$$

3) Diagram Konteks

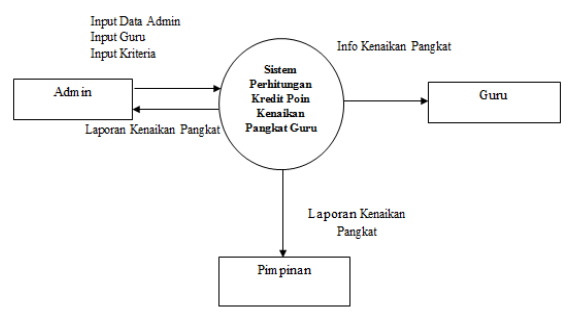

Gambar 1. Diagram Konteks

4) Entiti Relationship Diagram(ERD

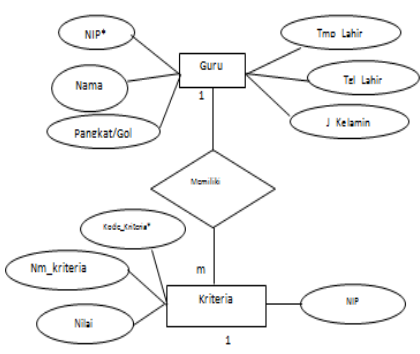

Gambar 2. Entiti Relationship Diagram(ERD) 


\section{5) Rancangan File Database}

Perancangan database dilakukan supaya isi situs dapat diorganisasi dan dirawat dengan mudah dan baik. Penulis menggunakan beberapa tabel dalam pengembangan situs ini antara lain sebagai berikut:

1. File Admin

$\begin{array}{ll}\text { Nama File } & \text { : Admin } \\ \text { Primary Key } & \text { : Username }\end{array}$

\begin{tabular}{|l|l|l|}
\hline \multicolumn{1}{|c|}{ Field } & \multicolumn{1}{|c|}{ Type } & \multicolumn{1}{c|}{ Keterangan } \\
\hline Usemamt & Varchar (10) & Usemame \\
\hline Passurord & Varchar (5) & Passurord Admin \\
\hline
\end{tabular}

2. File Guru

Nama File : Guru

Primary Key : NIP

\begin{tabular}{|c|c|c|}
\hline Field & Type & Keterangan \\
\hline $\mathrm{NP}$ & Varchar (15) & Nomor Indtk Grou \\
\hline Nama & Varthar (25) & Nema Guru \\
\hline Tempa__Lahir & Varthar (25) & Terpat Lahir \\
\hline Igl_lahir & Dete & Tanggl lahir \\
\hline J_Relamin & Varchar (15) & Jenis Kelamin \\
\hline Panglat Col & Varthar (25) & Panglat Sekrang \\
\hline
\end{tabular}

3. File Kriteria
Nama File
: Kriteria
Primary Key : Kode_Kriteria

\begin{tabular}{|c|c|c|}
\hline Field & Ippe & Ketenngun \\
\hline Boda-Srtiteria & $\operatorname{Int}(3)$ & Kode Kriteria \\
\hline $\mathrm{NP}$ & Varthe (1.5) & Nonor lnd: Gro \\
\hline N_Énteria & Varche (1.) & Nana Krieria \\
\hline Nai & $\operatorname{Int}(5)$ & Nei Kriteria \\
\hline
\end{tabular}

\section{6) Rancangan Tampilan}

Rancangan tampilan merupakan rancangan tampilan halaman yang akan digunakan oleh admin untuk menghitung angka kredit point guru. Adapun rancangan menu tampilan adalah sebagai berikut:

\section{Rancangan Tampilan Halaman Login}

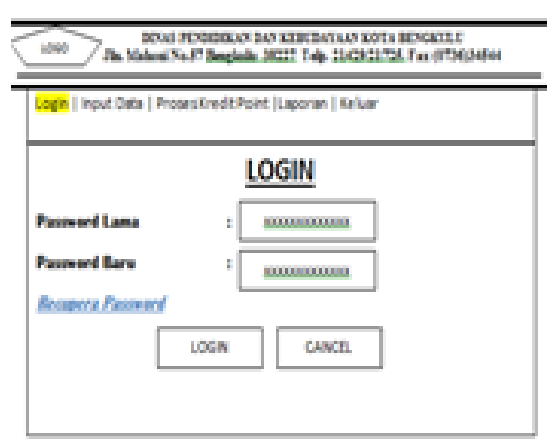

Gambar 3 Tampilan Halaman Login

Rancangan Tampilan Halaman Data Guru

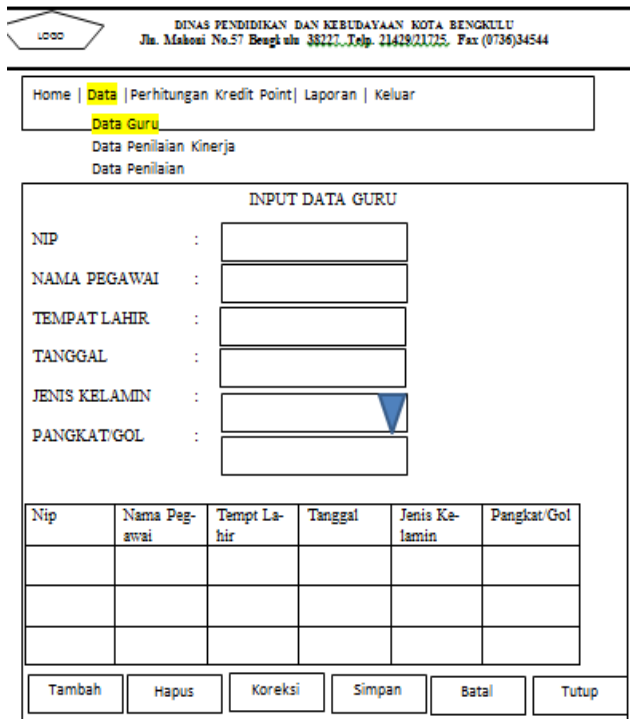

Gambar 4 Tampilan Halaman Input Data Guru

Rancangan Tampilan Halaman Data Penilaian Kinerja

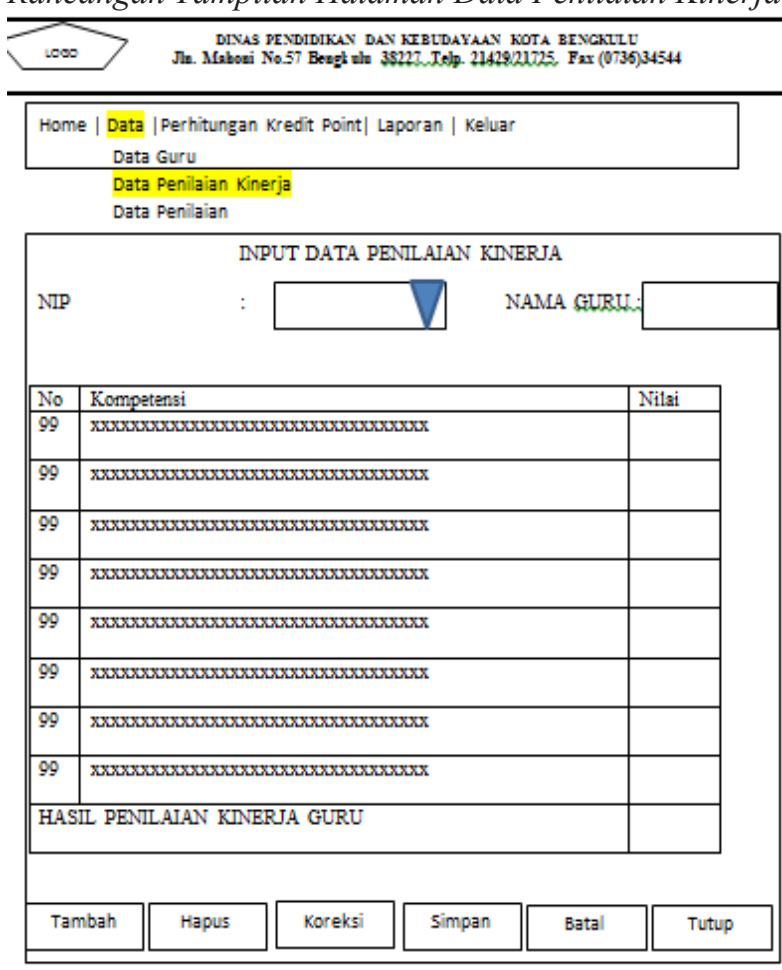

Gambar 5 Tampilan Halaman Penilaian Kinerja 


\section{Rancangan Tampilan Halaman Data Penilaian}

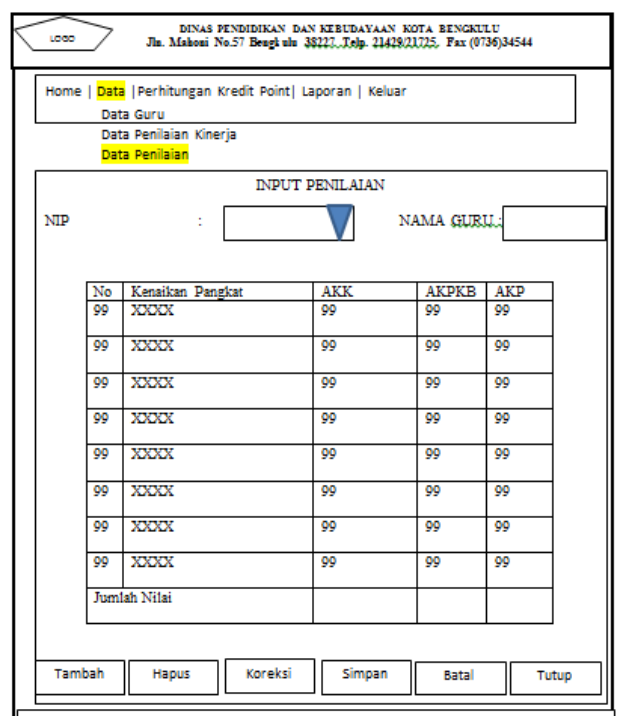

Gambar 6 Tampilan Halaman Data Penilaian Guru

Rancangan Tampilan Halaman Perhitungan Angka Kredit Point

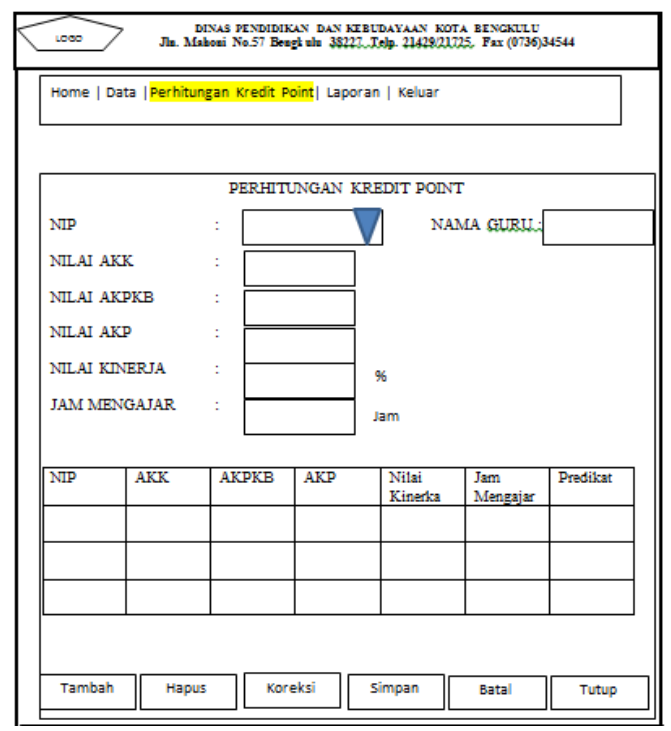

Gambar 7 Tampilan Halaman Perhitungan Kredit Point

\section{Rancangan Tampilan Halaman Laporan}

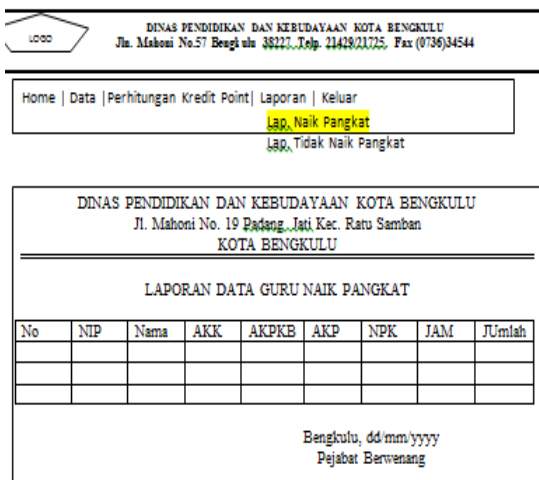

Gambar 8 Tampilan Halaman Laporan Guru Naik Pangkat
Rancangan Tampilan Halaman Data Penilaian

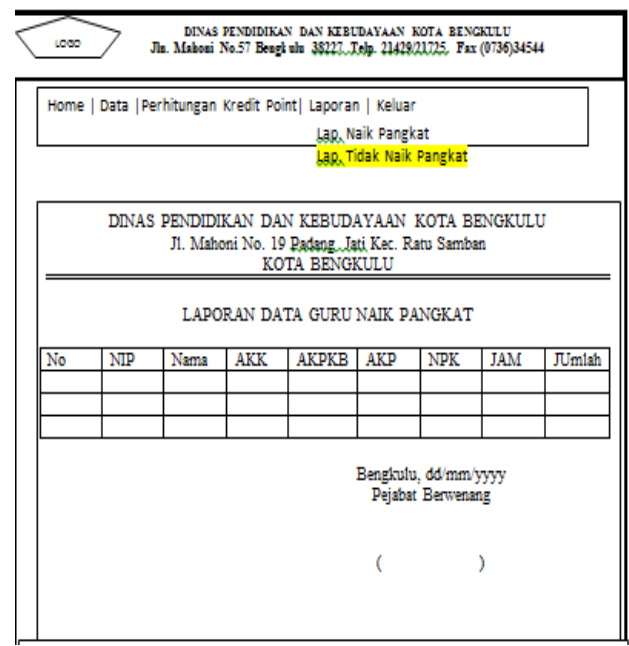

Gambar 9. Tampilan Halaman Laporan Guru Tidak Naik Pangkat

\section{7) Perancangan Pengujian}

Pengujian sistem dilakukan untuk memeriksa kekompakan atau kinerja antar komponen sistem yang diimplementasikan. Tujuan utama dari pengujian sistem adalah untuk memastikan bahwa elemen-elemen atau komponen-komponen dari sistem telah berfungsi sesuai dengan yang diharapkan.

Pengujian utama sistem menggunakan server localhost. Kemudian melakukan pengujian Black Box untuk mengetahui apakah perangkat lunak sudah berfungsi dengan benar. Pengujian tersebut dilakukan secara langsung di Dinas Pendidikan dan Kebudayaan Kota Bengkulu. Selain itu pengujian juga dilakukan dengan penyebaran kuisioner kepada calon pengguna sistem.

\section{IV.Pembahasan}

\section{A. Hasil Program dan Pembahasan}

Aplikasi perhitungan kredit point untuk pengajuan kenaikan pangkat guru pada Dinas Pendidikan dan Kebudayaan Kota Bengkulu ini dirancang menggunakan Bahasa VB 6.0. Masing-masing menu telah berjalan sesuai fungsinya masing-masing. Tampilan menu-menu sistem akan diuraikan satu per satu pada pembahasan di bawah ini : 


\section{1) Tampilan Halaman Login}

Halaman ini digunakan oleh admin untuk login ke sistem. Sehingga admin dapat meng-input, mang-update dan men-delete serta mencetak laporan data. Halaman login dapat dilihat pada gambar 10.

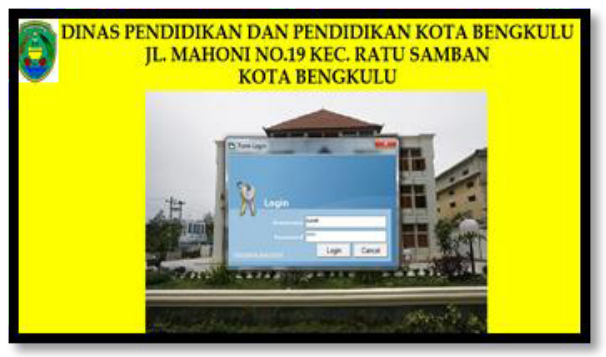

Gambar 10. Tampilan Halaman Login

\section{2) Tampilan Input Data Guru}

Halaman ini digunakan oleh admin untuk memasukkan data guru yang akan di nilai untuk kenaikan pangkat. Halaman input data guru dapat dilihat pada gambar 11.

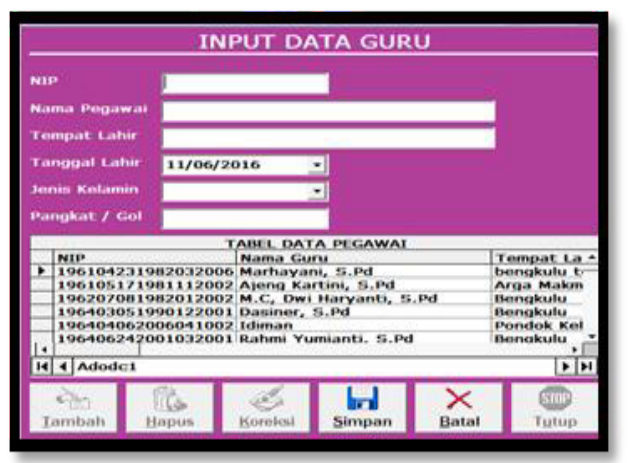

Gambar 11. Tampilan Input Data Guru

\section{3) Tampilan Input Data Penilaian Kinerja Guru}

Halaman ini digunakan oleh admin untuk memasukkan data penilaian kinerja guru ke dalam sistem. Halaman input data penialaian kinerja guru dapat dilihat pada gambar 12 .

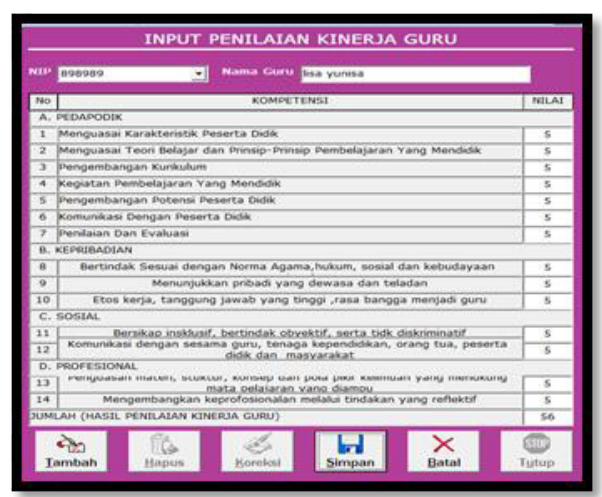

Gambar 12.Tampilan Input Data Penilaian Kinerja Guru
Pada gambar 12 di atas, dijelaskan bahwasanya hasil data penilaian kinerja guru didapatkan dari masingmasing sekolah. Penilaian maksimum kinerja guru adalah 56. Pembahasan manual sudah di bahas pada bab sebelumnya. Setelah data kinerja guru di input maka klik button "simpan" untuk menyimpan data.

\section{4) Tampilan Input Data Penilaian Angka Kredit Guru}

Halaman ini digunakan oleh admin untuk memasukkan data penilaian angka kredit guru ke dalam sistem. Halaman input data penialaian angka kredit guru dapat dilihat pada gambar 13 .

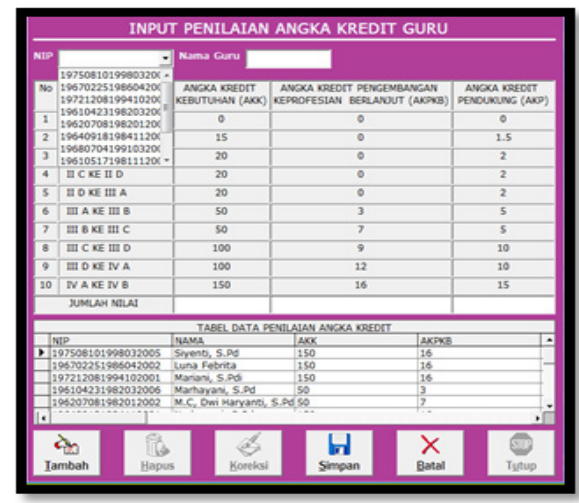

Gambar 13. Tampilan Input Data Penilaian Angka

$$
\text { Kredit Guru }
$$

Pada gambar 4.4 di atas, dijelaskan bahwa nilai AKK, AKPKB dan AKP guru di input berdasarkan kenaikan golongan guru, misalnya dari golongan III A ke III B. Maka data $\mathrm{AKK}=50, \mathrm{AKPKB}=3, \mathrm{AKP}=5$. Klik button "Simpan" untuk menyimpan data.

\section{5) Tampilan Proses Perhitungan Angka Kredit Point Guru}

Halaman ini digunakan oleh admin untuk memproses perhitungan kredit point guru. Halaman proses kredit point guru dapat dilihat pada gambar 14 .

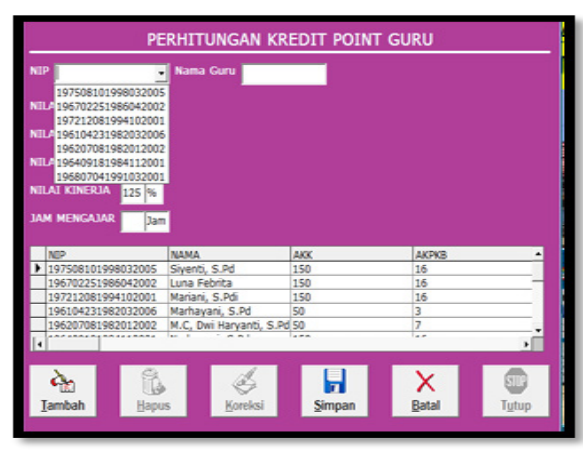

Gambar 14. Tampilan Input Data Penilaian Angka Kredit Guru 
Pada gambar 4.5 di atas dijelaskan bahawa halaman ini digunakan untuk memproses data kredit point guru, yang mana masing-masing nilai AKK, AKPKB, AKP dan kinerja didapatkan dari proses input data masing-masing guru sebelumnya. Pada hlaman ini hanya ditambahkan jam mengajar guru, yang nilai maksimumnya 24 jam. Sehingga setelah diproses akan didapatkan laporan guru yang dapat naik pangkat sesuai dengan penilaian yang telah dilakukan. Klik button "Simpan" untuk menyimpan data.

\section{6) Tampilan Laporan Kenaikan Pangkat Guru}

Halaman ini digunakan oleh admin mencetak laporan kenaikan pangkat guru. Laporan ini terdiri dari 2 bagian, antara lain sebagai berikut:

\section{7) Laporan Guru Naik Pangkat}

Laporan ini berisi informasi laporan data guru yang naik pangkat, seperti gambar 15 .

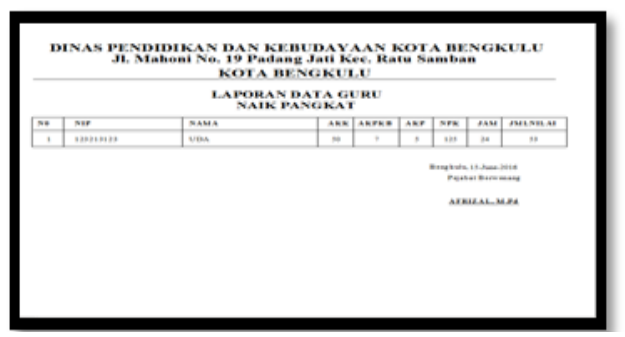

Gambar 15. Tampilan Laporan Guru Naik Pangkat

8) Laporan Guru yang Tidak Naik Pangkat

Laporan ini berisi informasi laporan data guru yang tidak naik pangkat, seperti gambar 16

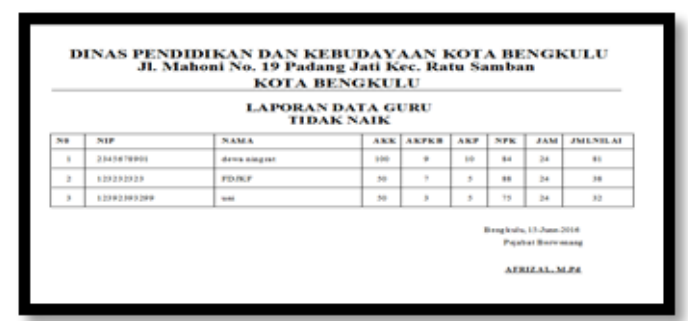

Gambar 16. Tampilan Laporan Guru Tidak dapat Naik Pangkat

\section{Penutup}

\section{A. Kesimpulan}

Dari penulisan laporan penelitian ini mulai dari tahapan analisa permasalahan yang ada hingga pengujian applikasi sistem yang baru maka dapat diambil bebrapa kesimpulan, yaitu:
1. Bahasa pemrograman VB 6.0 dapat memberikan kemudahan dalam pembangunan aplikasi perhitungan kredit point untuk pengajuan kenaikan pangkat guru pada Dinas Pendidikan dan Kebudayaan Kota Bengkulu.

2. Aplikasi perhitungan kredit point untuk pengajuan kenaikan pangkat guru pada Dinas Pendidikan dan Kebudayaan Kota Bengkulu ini dapat memberikan kemudahan dalam perhitungan angka kredit guru untuk proses kenaikan pangkat.

\section{B. Saran-saran}

Agar sistem yang diusulkan dapat digunakan lebih optimal dan dapat berjalan sesuai dengan yang diharapkan, maka ada beberapa saran yang dapat dijadikan bahan pertimbangan untuk pihak Dinas Pendidikan dan Kebudayaan Kota Bengkulu.

1. Sistem yang dibangun harus dapat di mengerti oleh pengguna nantinya husus pada aplikasi perhitungan kredit point untuk pengajuan kenaikan pangkat guru pada Dinas Pendidikan dan Kebudayaan Kota Bengkulu. Sehingga diharapkan adanya pengembangan lagi untuk sistem yang lebih luas cakupannya.

2. Diperlukan maintenace terhadap program atau aplikasi yang telah dibuat, supaya dapat digunakan secara berkelanjutan selama kebutuhan terhadap informasi yang ada di Dinas Pendidikan dan Kebudayaan Kota Bengkulu.

\section{DAFTAR Pustaka}

Adi Kurniadi. 2000. Pemograman Microsoft Visual Basic 6.0. Penerbit Elex Media Komputindo : Jakarta.

Ems, TIM. 2012. Web Programming for Beginners. Jakarta: PT Elex Media Komputindo.

Jogiyanto, Hartono, 1999, Analisis \& Desain Sistem Informasi : Pendekatan. Terstruktur Teori dan Praktek Aplikasi Bisnis, Andi Offset,

Undang-Undang Peraturan Menteri Pendayagunaan Aparatur Negara dan Reformasi Birokrasi Nomor 16 Tahun 2009 tentang Jabatan Fungsional Guru dan ANgka Kreditnya.

Yakub, 2012, Pengantar Teknologi Informasi, Graha Ilmu, Yogyakarta. 